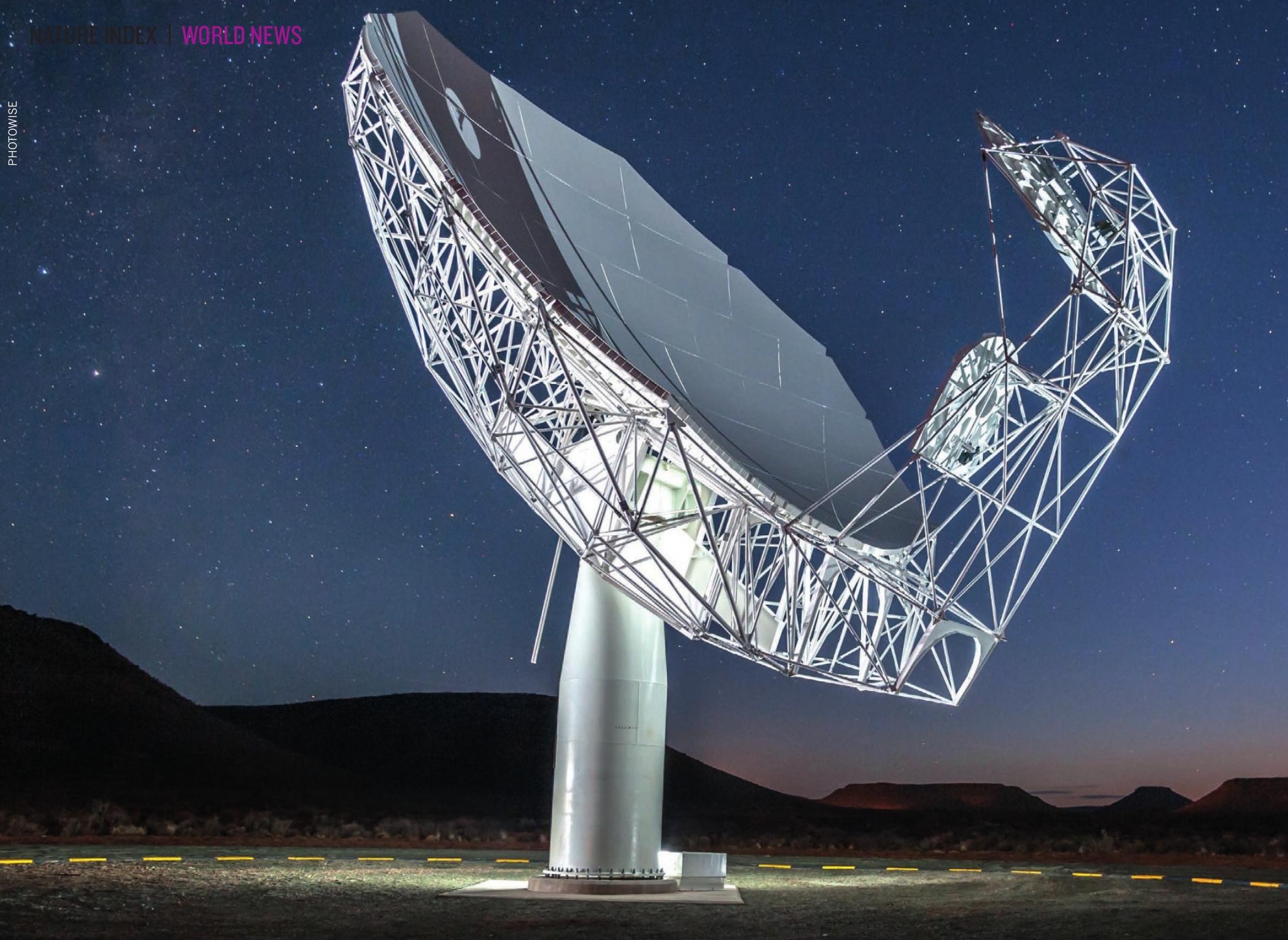

\title{
A BEACON IN THE BUSH BECOMES AN ASTRONOMY POWERHOUSE
}

\author{
South Africa's University of the Western Cape has exceeded expectations
}

\section{BY LINDA NORDLING}

The people behind South Africa's apartheid regime never meant for the University of the Western Cape (UWC) on the outskirts of Cape Town to excel at anything. Created in 1960 as a 'bush college' to provide black South Africans with limited training, it was not expected to compete with the country's well-resourced research universities. UWC's squat buildings were erected far from the city's wealthy shopping malls, leafy parks and pristine beaches.

But UWC is not defined by its past. Since the fall of apartheid in 1994, the university has an impressive record, increasing its articles in the Web of Science from 31 that year to 657 in 2015. In 2014 the university ranked fifth in South Africa for the number of staff with PhDs.

But, it is in physical sciences that the university really holds its own with South Africa's elite institutions. The university's contribution to physical science research in the Nature Index, measured by weighted fractional count (WFC), more than doubled between 2012 and 2015.

Over the same time, the University of Cape Town, which boasts a century of academic excellence, saw its WFC in physical science fall slightly.

UWC's rise in the index is largely due to publications in astronomy, says Roy Maartens, the head of the physics department's astronomy research group. Maartens returned from the United Kingdom to his native South Africa in 2011 to take up UWC's new chair in radio astronomy.

The position was part of the government's push to boost the country's chances of winning its bid to host the Square Kilometre Array (SKA), a giant radio telescope. South Africa was a joint winner with Australia. The telescope will comprise thousands of radio antennae spread across a vast area, including countries further north in Africa.

\section{ASTRONOMICAL AMBITIONS}

Investments in the SKA have helped expand UWC's astronomy group to six staff, 15 postdoctoral researchers and 13 postgraduate students. The group is leading efforts to turn the SKA into a state-of-the-art cosmology experiment, probing the structure of dark energy and testing Einstein's general theory of relativity.

The achievements of the university's faculty offer great personal satisfaction to staff such as materials science professor Reggie Madjoe, who could only study at UWC. "I have to pinch myself," he says. UWC's students are still mostly non-white, but this makes its academic successes all the more vital for the future of 
